\title{
DNA methylation of FKBP5 in South African women: associations with obesity and insulin resistance
}

Tarryn Willmer ${ }^{1,2^{*}}$ D, Julia H. Goedecke ${ }^{3,4}$, Stephanie Dias ${ }^{1}$, Johan Louw ${ }^{1,5}$ and Carmen Pheiffer ${ }^{1,2}$

\begin{abstract}
Background: Disruption of the hypothalamic-pituitary-adrenal (HPA) axis, a neuroendocrine system associated with the stress response, has been hypothesized to contribute to obesity development. This may be mediated through epigenetic modulation of HPA axis-regulatory genes in response to metabolic stressors. The aim of this study was to investigate adipose tissue depot-specific DNA methylation differences in the glucocorticoid receptor $(G R)$ and its co-chaperone, FK506-binding protein 51 kDa (FKBP5), both key modulators of the HPA axis.
\end{abstract}

Methods: Abdominal subcutaneous adipose tissue (ASAT) and gluteal subcutaneous adipose tissue (GSAT) biopsies were obtained from a sample of 27 obese and 27 normal weight urban-dwelling South African women. DNA methylation and gene expression were measured by pyrosequencing and quantitative real-time PCR, respectively. Spearman's correlation coefficients, orthogonal partial least-squares discriminant analysis and multivariable linear regression were performed to evaluate the associations between DNA methylation, messenger RNA (mRNA) expression and key indices of obesity and metabolic dysfunction.

Results: Two CpG dinucleotides within intron 7 of FKBP5 were hypermethylated in both ASAT and GSAT in obese compared to normal weight women, while no differences in $G R$ methylation were observed. Higher percentage methylation of the two FKBP5 CpG sites correlated with adiposity (body mass index and waist circumference), insulin resistance (homeostasis model for insulin resistance, fasting insulin and plasma adipokines) and systemic inflammation (c-reactive protein) in both adipose depots. GR and FKBP5 mRNA levels were lower in GSAT, but not ASAT, of obese compared to normal weight women. Moreover, FKBP5 mRNA levels were inversely correlated with DNA methylation and positively associated with adiposity, metabolic and inflammatory parameters.

Conclusions: These findings associate dysregulated FKBP5 methylation and mRNA expression with obesity and insulin resistance in South African women. Additional studies are required to assess the longitudinal association of FKBP5 with obesity and associated co-morbidities in large population-based samples.

Keywords: Obesity, Insulin resistance, Glucocorticoid receptor, FKBP5, DNA methylation, Adipose tissue

\footnotetext{
*Correspondence: tarryn.willmer@mrc.ac.za

'Biomedical Research and Innovation Platform, South African Medical

Research Council, Tygerberg 7505, South Africa

${ }^{2}$ Division of Medical Physiology, Faculty of Health Sciences, Stellenbosch

University, Tygerberg 7505, South Africa

Full list of author information is available at the end of the article
}

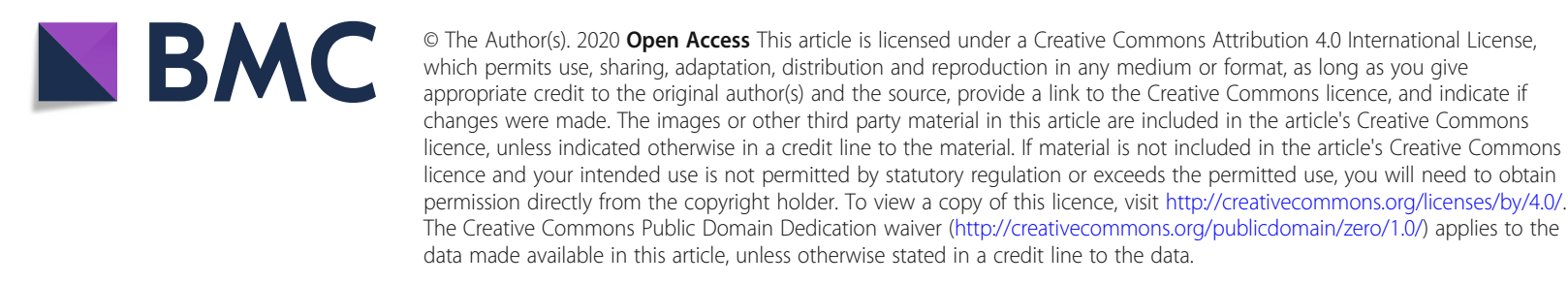




\section{Background}

The pathophysiology of obesity involves a complex interplay between genetic and environmental influences [1]. The interaction between these factors in disease development may be mediated through dysregulation of the hypothalamic-pituitary-adrenal (HPA) axis, a neuroendocrine system that plays a critical role in maintaining metabolic homeostasis in response to metabolic stressors, such as chronically high ambient levels of stress, reduced physical activity and consumption of high caloric foods that are readily available in a Western society [2]. The activity of the HPA axis is regulated by glucocorticoids, which convey their signals through the glucocorticoid receptor (GR), a transcriptional regulator [3]. The sensitivity of cells to glucocorticoid action is tightly regulated in part, through the interaction of GR with the co-chaperone, FK506-binding protein $51 \mathrm{kDa}$ (FKBP5), which negatively regulates GR signaling by inhibiting its binding to glucocorticoids and impeding translocation to the nucleus [4]. In turn, FKBP5 expression is transcriptionally activated by GR, which binds glucocorticoid response elements (GREs) present in the FKBP5 promoter and distal intronic regions, thus forming an ultra-short feedback loop [4]. Interestingly, a single nucleotide polymorphism (SNP) in FKBP5, specifically the T "risk allele" of the C/T SNP rs1360780 located in intron 2 , has previously been demonstrated to enhance FKBP5 transcription by moderating GRinduced epigenetic changes at multiple intronic GREs, including those within intron 7 [5].

Recently, increased DNA methylation of loci within $G R$ and FKBP5 has been identified as potential markers of HPA axis dysfunction $[6,7]$. DNA methylation involves the covalent addition of a methyl group to carbon $\mathrm{C} 5$ of cytosine dinucleotides to create 5-methylcytosine $(5 \mathrm{mC})$ [8]. This can result in an altered chromatin state and elicit long-term changes in gene expression and pathological dysfunctions [8]. Importantly, unlike genetic mutations, DNA methylation is reversible and therapies targeting DNA methyltransferases have been successfully applied to the management of certain neoplastic diseases [9]. Understanding the role of DNA methylation modifications in HPA axis regulation may lead to unique opportunities for preventive and therapeutic interventions aimed at restoring HPA axis function in metabolic diseases.

White adipose tissue (WAT), the primary site for energy storage in mammals, is distributed throughout the body in several depots which differ in structural organization, cellular function and associated risk for developing metabolic disease [10-12]. While abdominal obesity is more closely associated with metabolic disease due to its greater contribution to the systemic free fatty acid pool and chronic low-grade inflammation, accumulation of lower body (i.e. gluteal) fat is associated with a reduced incidence of type 2 diabetes (T2D) and cardiovascular disease (CVD), possibly owing to reduced lipolytic potential and greater differentiation capacity of adipocytes within this depot [13]. While the mechanisms underlying these depot differences in metabolic risk remain elusive, it has been speculated that intrinsic variations in gene expression and epigenetic signatures between adipose depots may be responsible $[11,13,14]$.

There is accumulating evidence to suggest that disruption of genes within the HPA axis may play a causal role in obesity and associated metabolic diseases [15-27]. However, to the best of our knowledge, no studies have examined the potential pathologic epigenetic modulation of HPA axis-regulatory genes in adipose tissue, a highly active endocrine organ and primary energy reservoir in humans. The aim of the current study was therefore to determine [1] the DNA methylation profiles of GR and FKBP5 in gluteal (GSAT) and abdominal (ASAT) WAT from obese and normal weight South African women, and [2] the association of these methylation profiles with markers of adiposity, insulin resistance and inflammatory status. We propose that hypermethylation of $G R$ and $F K B P 5$, key HPA axis-regulatory genes, is associated with metabolic dysfunction and that assessing methylation patterns of GR and FKBP5 in GSAT and ASAT depots may provide a better understanding of the intrinsic differences between abdominal and lower body obesity.

\section{Results}

\section{Participant characteristics}

The characteristics of participants in this study have been described in detail previously [28] and are summarized in Table 1. The participants were all female, $51.85 \%$ black and $48.15 \%$ white South African. The obese women were significantly older than normal weight women $(p=0.004)$. There were no significant differences in socioeconomic score (SES), current smoking status or weekly alcohol consumption between obese and normal weight women.

By design, all measures of body composition and fat distribution were greater in obese compared to normal weight women. While no differences in fasting glucose levels were observed between the groups, the obese women displayed higher systemic inflammation (as measured by c-reactive protein), hyperinsulinemia and insulin resistance (as measured by homeostasis model for insulin resistance (HOMA-IR), increased leptin and reduced adiponectin concentrations) and reduced insulin sensitivity $\left(S_{\mathrm{I}}\right)$ compared to normal weight women.

\section{GR and FKBP5 methylation analyses}

We used pyrosequencing to analyse $18 \mathrm{CpG}$ sites situated within exon $1 \mathrm{~F}$ of the proximal GR promoter (Fig. 1a), as well as $13 \mathrm{CpG}$ sites within intron 2 and two CpG sites within intron 7 of FKBP5 (Fig. 1b). 
Table 1 Participant characteristics

\begin{tabular}{|c|c|c|c|}
\hline & Normal weight $(n=27)$ & Obese $(n=27)$ & $P$ value \\
\hline \multicolumn{4}{|c|}{ DEMOGRAPHIC AND LIFESTYLE FACTORS } \\
\hline Age (years) & $24(22-26)$ & $28(24-36)$ & 0.004 \\
\hline \multicolumn{4}{|l|}{ Ethnicity } \\
\hline Black $^{a}$ & $14(51.9)$ & $14(51.9)$ & \\
\hline SES & $16.8(11.6-22.6)$ & $20.1(10.6-23.1)$ & 0.843 \\
\hline Smoking (yes) $)^{a}$ & $7(25.9)$ & $7(25.9)$ & 0.936 \\
\hline Alcohol consumption (g) & $4.7(0-24.6)$ & $3.8(0-16.1)$ & 0.854 \\
\hline \multicolumn{4}{|l|}{ BODY COMPOSITION } \\
\hline BMI $\left(\mathrm{kg} / \mathrm{m}^{2}\right)$ & $22.9(21.7-23.7)$ & $38.3(34.3-41.6)$ & $<0.001$ \\
\hline Fat (\%) & $29.7(25.9-35.1)$ & $47.0(43.5-49.6)$ & $<0.001$ \\
\hline \multicolumn{4}{|l|}{ BODY FAT DISTRIBUTION } \\
\hline Waist circumference $(\mathrm{cm})$ & $78.3(74.0-82.0)$ & $112.5(102.6-118.5)$ & $<0.001$ \\
\hline GSAT (kg) & $4.6(4.0-5.2)$ & $5.9(5.4-6.5)$ & 0.001 \\
\hline ASAT $\left(\mathrm{cm}^{2}\right)$ & $169.7(134.7-225.6)$ & $558.2(480.2-620.3)$ & $<0.001$ \\
\hline VAT $\left(\mathrm{cm}^{2}\right)$ & $54.3(42.6-77.2)$ & $107.7(80.3-173.7)$ & $<0.001$ \\
\hline \multicolumn{4}{|l|}{ METABOLIC PARAMETERS } \\
\hline Fasting Glucose (mmol/L) & $4.4(4.1-4.6)$ & $4.5(4.4-4.7)$ & 0.027 \\
\hline Fasting Insulin (mU/L) & $5.1(3.5-8.5)$ & $12.5(7.1-16.9)$ & 0.001 \\
\hline HOMA-IR & $0.9(0.7-1.7)$ & $2.5(1.1-3.3)$ & $<0.001$ \\
\hline $\mathrm{S}_{\mathrm{I}}\left(\cdot 10^{-4} \mathrm{~min}^{-1} /[\mu \mathrm{U} / \mathrm{ml}]\right)$ & $4.1(1.4-6.2)$ & $1.8(1.0-3.6)$ & 0.011 \\
\hline C-reactive protein (mg/l) & $1.2(0.6-3.8)$ & $7.9(3.4-8.7)$ & $<0.001$ \\
\hline Adiponectin (ng/ml) & $6.5(4.1-9.5)$ & $3.5(2.1-5.8)$ & $<0.001$ \\
\hline Leptin (ng/ml) & $15.2(7.8-20.5)$ & $59.0(47.9-66.2)$ & $<0.001$ \\
\hline
\end{tabular}

Data expressed as the median (25th-75th percentile) or as ${ }^{\text {a }}$ count (percentage)

Abbreviations: BMI body mass index, GSAT gluteal subcutaneous adipose tissue, HOMA-IR Homeostatic model of insulin resistance, SAT subcutaneous adipose tissue, SES socioeconomic score, $S_{1}$ insulin sensitivity index, VAT visceral adipose tissue

\section{A}

GR: Chr. 5

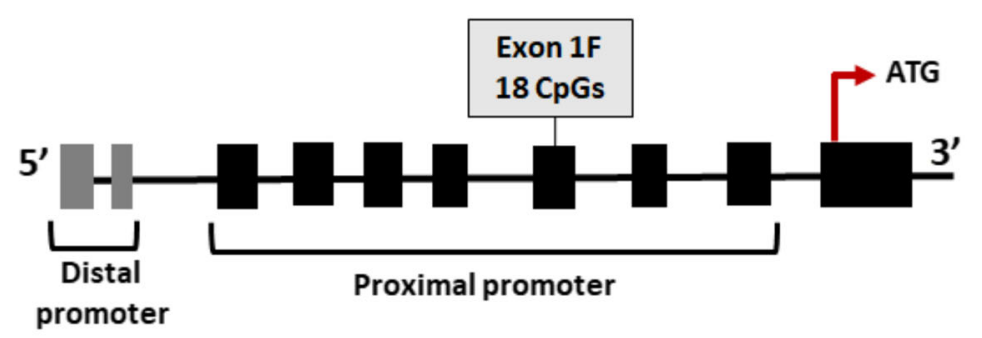

B

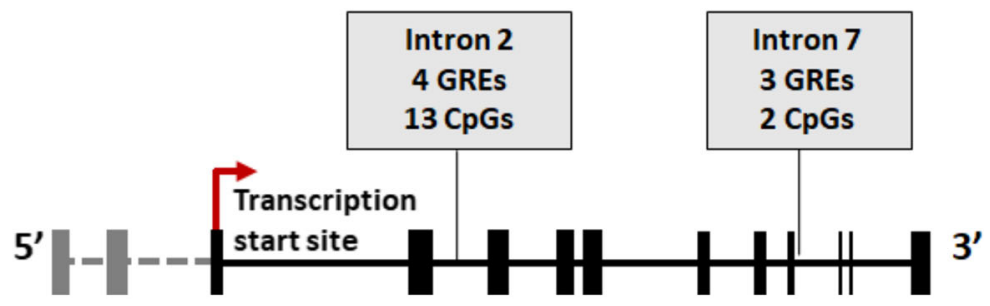

Fig. 1 Schematic diagram of the $\mathbf{a}$ GR and $\mathbf{b}$ FKBP5 genes, illustrating the CpG sites analysed in the proximal $1 \mathrm{~F}$ promoter and introns 2 and 7 , respectively. The transcription start sites and glucocorticoid response elements (GREs) within FKBP5 are indicated 


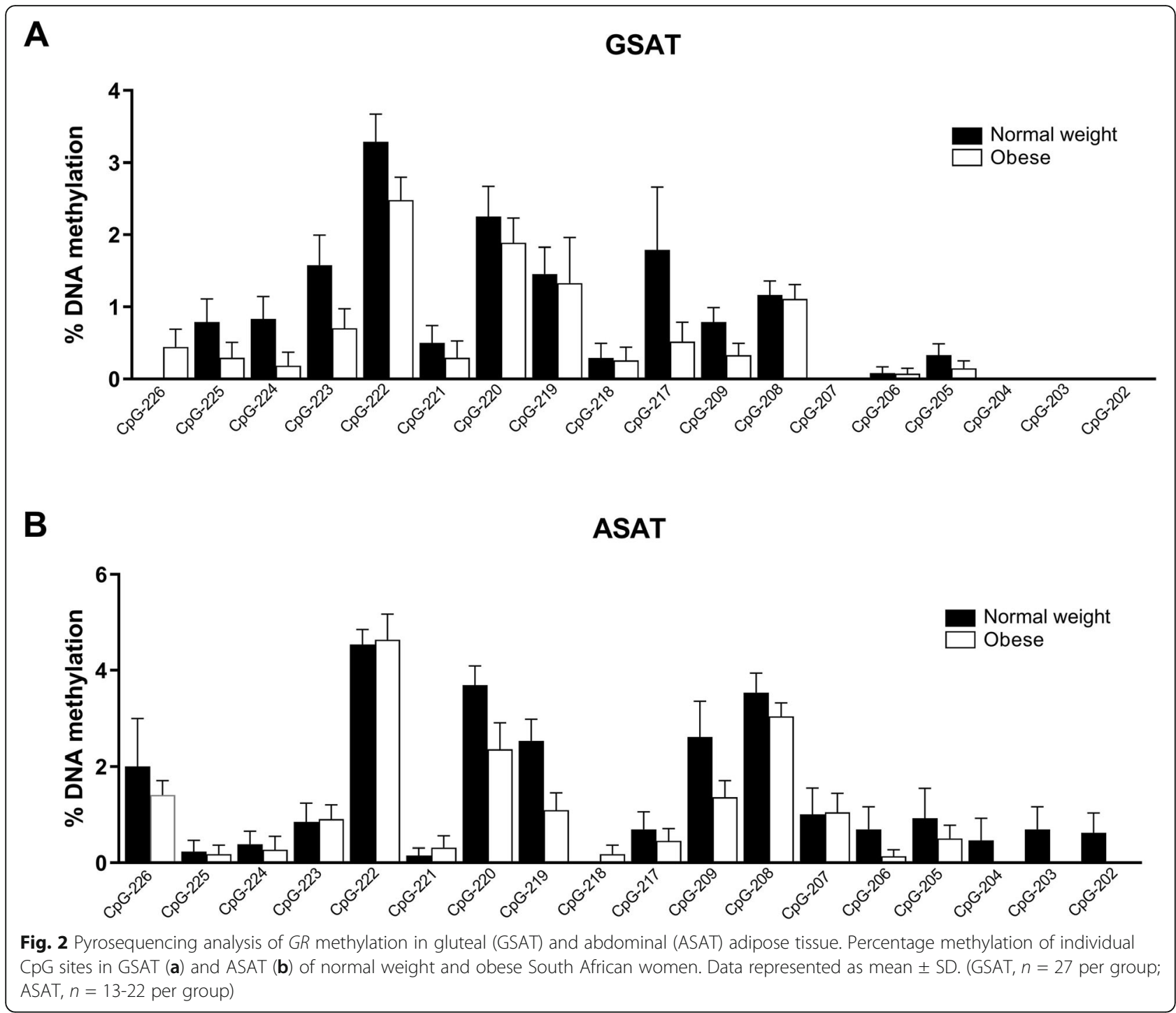

Methylation of GR and FKBP5 were analysed in GSAT and ASAT biopsies as representatives of lower body and central obesity, respectively.

Results revealed low GR methylation levels in both GSAT (Fig. 2a) and ASAT (Fig. 2b) depots, as well as a large degree of inter-individual variation at all $\mathrm{CpG}$ sites, irrespective of obesity. In GSAT, GR methylation appeared to be lower in obese women compared to normal weight women, although these differences were not significant (Fig. 2a). No consistent differences in DNA methylation patterns in ASAT were observed between obese compared to normal weight women (Fig. 2b).

An analysis of FKBP5 intron 2 methylation levels in GSAT and ASAT revealed no significant differences between obese compared to normal weight women (Fig. 3a, b). For FKBP5 intron 7, methylation levels of CpG542 (137,847 bp from TSS) and CpG543 (137,872 bp from
TSS) were approximately $10 \%$ higher in obese compared to normal weight women (GSAT, $p<0.001$; ASAT, $p<0.001)$, which was consistent for both depots (Fig. 3a, b).

\section{FKBP5 methylation associations with obesity and} parameters of metabolic function

The differential methylation patterns observed in obese versus normal weight women prompted us to further explore the associations of these $\mathrm{CpG}$ sites with clinical and biochemical features of obesity and metabolic dysfunction. We explored DNA methylation associations using orthogonal partial least-squares discriminate analysis (OPLS-DA) (Fig. 4). The OPLS score plot for each model revealed a separation between the obese and normal weight women (Fig. 4, top panels). The loading plots (Fig. 4, lower panels), which signify the basis of the score plot clustering, revealed that CpG542 and CpG543 were 


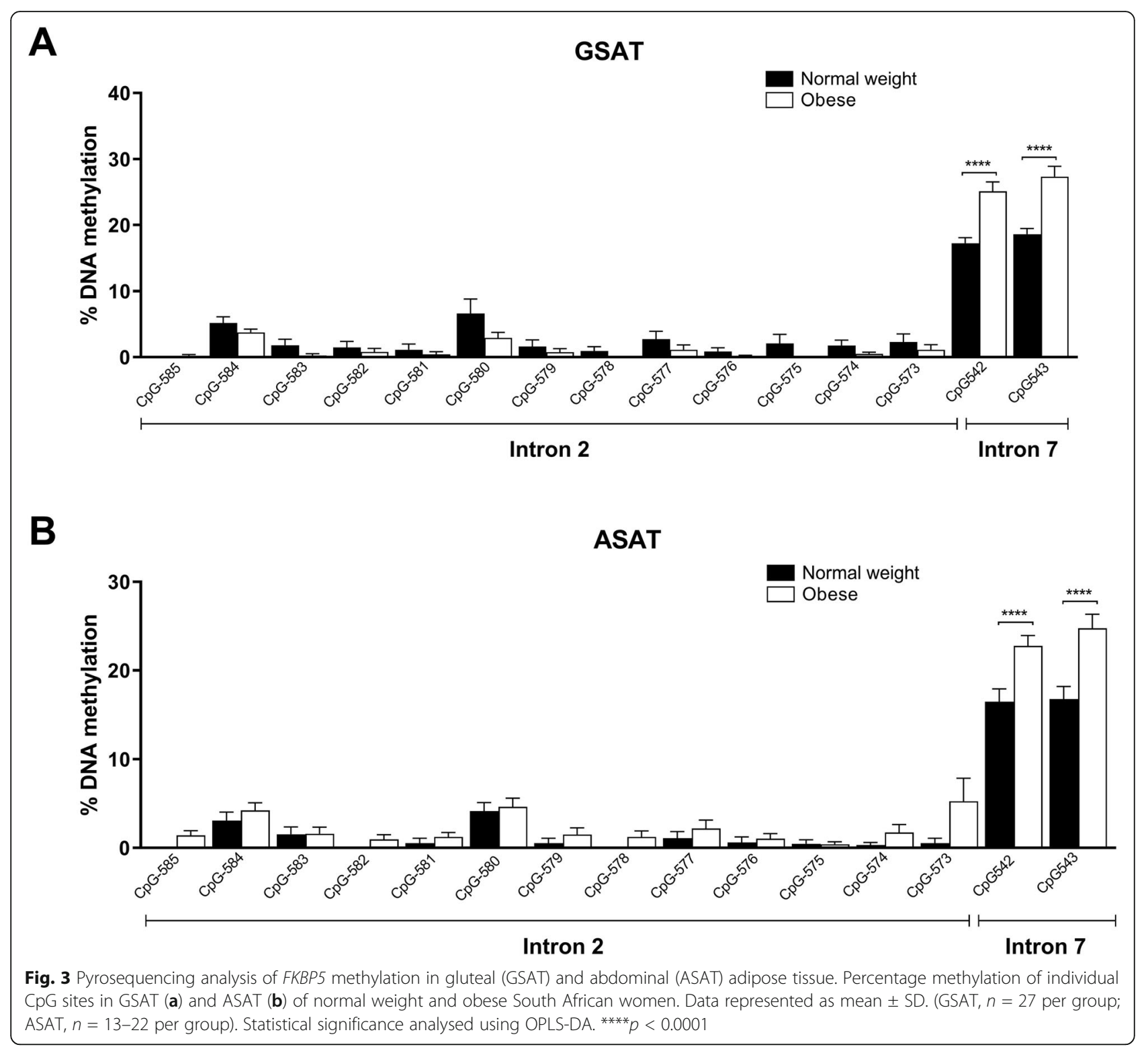

highly correlated between ASAT and GSAT (CpG542: rs $=0.698, p<0.001$; CpG543: $\mathrm{rs}=0.765, p<0.001)$, and positively associated with measures of adiposity, including BMI and waist circumference (WC) in both adipose depots. Similarly, positive associations were observed for markers of insulin resistance (HOMA-IR, fasting insulin, reduced insulin sensitivity, increased leptin and reduced adiponectin) and systemic inflammation (c-reactive protein). CpG542 and CpG543 methylation also significantly associated with ethnicity and SES in both depots. Additionally, CpG543 methylation associated with alcohol consumption in ASAT. Consequently, all associations were adjusted accordingly for significant covariates. When the adjustments were made, all associations were maintained; however, the associations with insulin sensitivity lost statistical significance (Table S1).
GR and FKBP5 mRNA expression levels in SAT

To examine whether altered CpG methylation corresponded with changes in GR and FKBP5 expression, we measured their messenger ribonucleic acid (mRNA) status in GSAT and ASAT using quantitative real-time PCR (qRT-PCR). GSAT from obese women had 30\% lower GR mRNA expression levels $(p<0.010)$ compared to normal weight women (Fig. 5a), while no differences were observed in ASAT (Fig. 5b). Similarly, FKBP5 mRNA expression levels in GSAT were reduced by $40 \%$ in obese compared to normal weight women (Fig. 5c) but was unchanged in ASAT (Fig. 5d). Correlation analyses revealed a significant inverse relationship between FKBP5 mRNA levels and CpG542/3 methylation in GSAT, but not in ASAT (Fig. 5e, f). Furthermore, FKBP5 mRNA negatively associated with markers of 


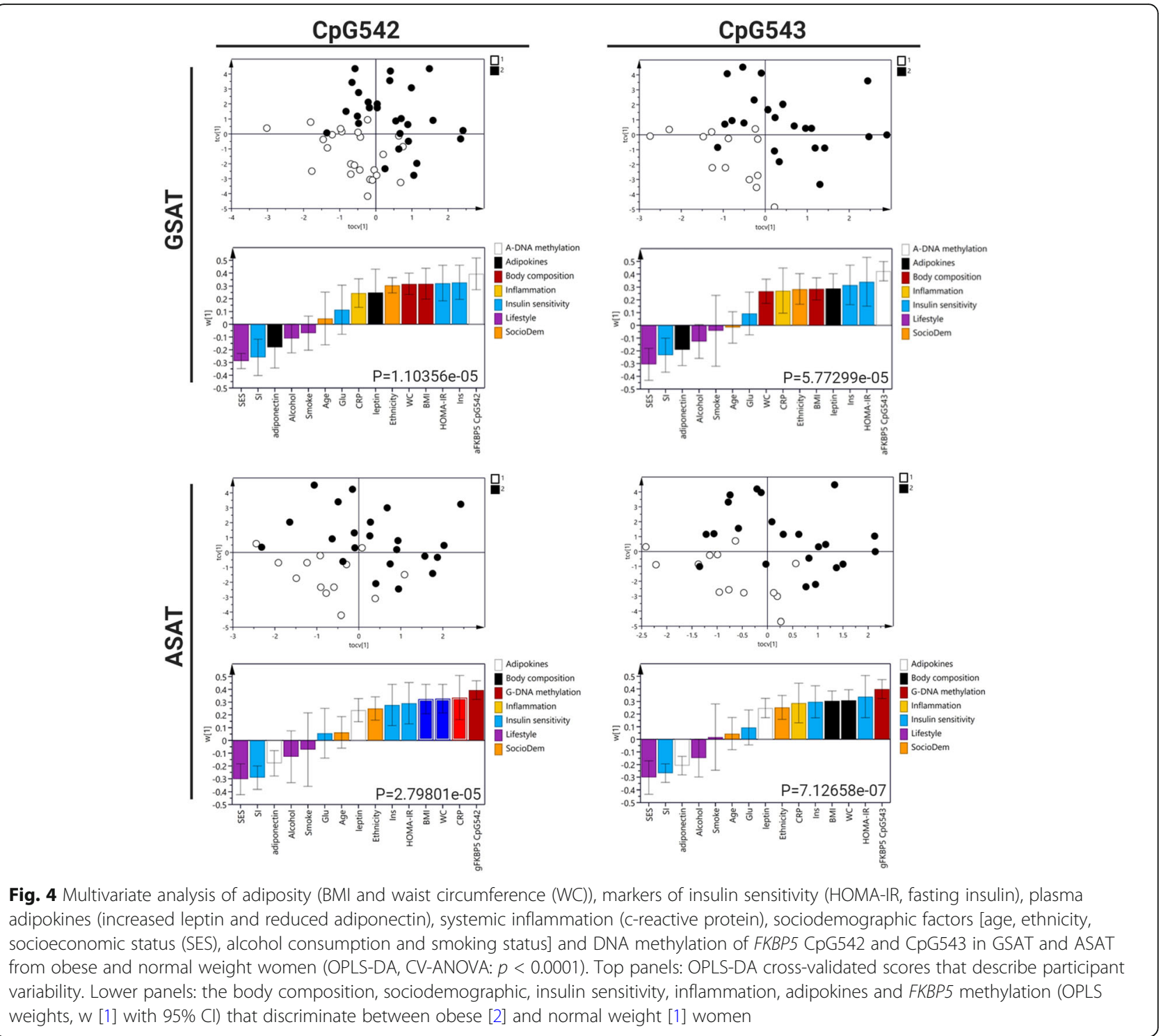

adiposity, insulin resistance and systemic inflammation in GSAT, but not in ASAT (Table S2).

\section{Effect of rs 1360780 SNP on FKBP5 methylation and gene expression}

In order to assess the potential moderating role of the rs1360780 SNP on FKBP5 methylation and gene expression data in our study, we genotyped all participants' SAT samples for this SNP. Using the combined sample of obese and normal weight participants, we determined the genotype frequencies to be $0.44(n=21), 0.38(n=19)$ and $0.16(n=6)$ for the CC, CT and TT (rare homozygous "risk allele") genotypes, respectively, and we observed no significant deviations from the Hardy-Weinberg equilibrium in this sample population $(p=0.12)$ (data not shown).

We next stratified the samples based on genotype and observed no significant differences in FKBP5 methylation at CpG543 (Fig. 6a) or CpG543 (Fig. 6b) between the CC, CT and TT genotypes in both GSAT and ASAT depots. Similarly, no differences were observed in FKBP5 mRNA expression between any of the genotypes in GSAT (Fig. 6c) or ASAT (Fig. 6d). Taken together, these data demonstrate that FKBP5 methylation and gene expression levels in obese and normal weight women in our study were not influenced by the rs1360780 SNP.

\section{Discussion}

Obese individuals have a higher risk of developing T2D and CVD; however, these diseases are often diagnosed years after the onset of insulin and glucose dysregulation, during which micro- and macrovascular complications can occur. It is thus crucial to understand the early pathogenic mechanisms of obesity and insulin resistance sequelae in order to develop early preventative interventions. Our present data provide 
A

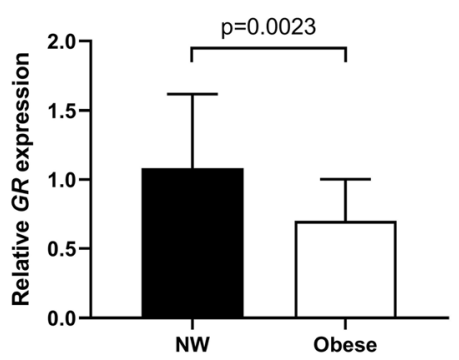

C

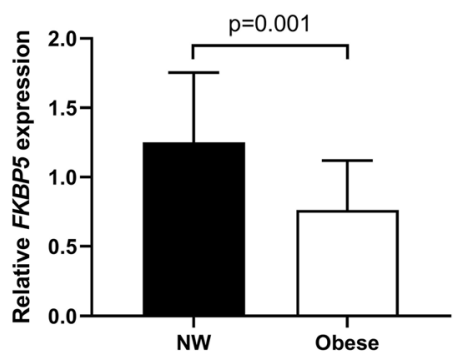

E

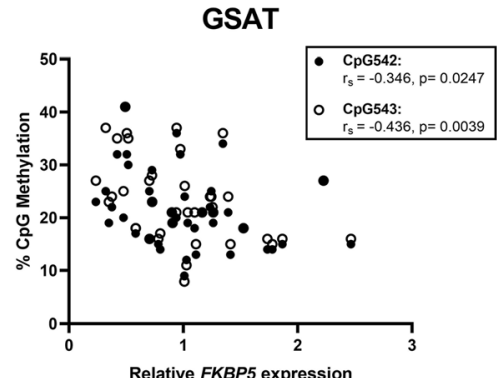

B

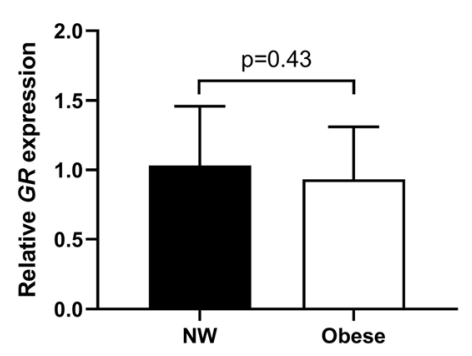

D

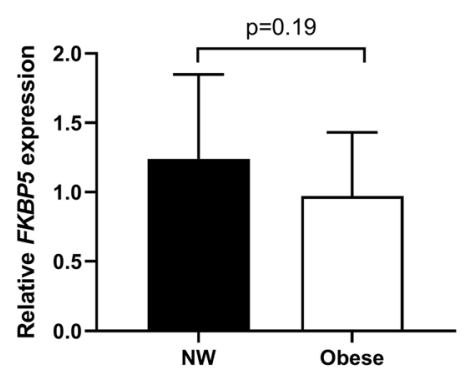

F ASAT

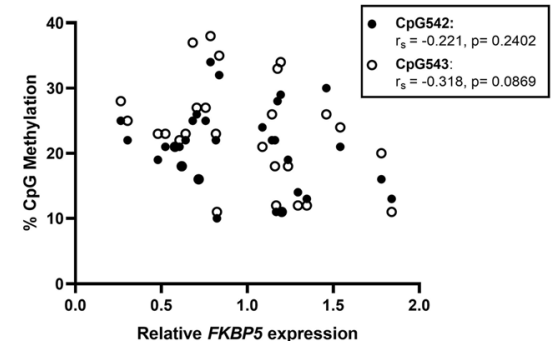

Fig. 5 GR and FKBP5 mRNA expression in gluteal (GSAT) and abdominal (ASAT) adipose tissue. Relative mRNA expression of GR in GSAT (a) and ASAT (b) and FKBP5 in GSAT (c) or ASAT (d) from normal weight (NW) and obese South African women. Data represent mean \pm SD (GSAT, $n=27$ per group; ASAT, $n=13-22$ per group). Spearman's correlation analysis of FKBP5 CpG542 and CPG543 methylation and FKBP5 mRNA levels in GSAT (e) and ASAT (f) from normal weight and obese black and white South African women ( $n=27$ per group). Linear regression lines used for descriptive purposes only

novel evidence that DNA methylation of two intronic CPG sites in FKBP5, a key player of the HPA axis and stress response, is altered in SAT from obese compared to normal weight women. Moreover, multivariable regression analysis of these CpG sites revealed a positive relationship with measures of adiposity (BMI and waist circumference), insulin resistance (HOMA-IR, fasting insulin, increased leptin and reduced adiponectin levels) and systemic inflammation (CRP), all of which are established risk factors for T2D and CVD.

Our analysis of $G R$ methylation within exon $1 F$ revealed considerable inter-individual variability in our sample population. This is consistent with a previous study assessing methylation of the same $G R$ promoter region in patients with subclinical atherosclerosis [27] and also agrees with other epigenetic studies in complex diseases [29]. While the magnitude of $G R$ methylation alterations between obese and normal weight women are less pronounced compared to those identified in, for example, various types of malignant disorders [30,31], they are consistent with genome-wide association studies showing subtle changes in GR methylation, including sites within exon $1 F$, in numerous disorders [32-34]. Furthermore, GR mRNA expression was downregulated in GSAT from our obese study population [19], and although its expression did not correlate with methylation levels (data not shown), it is now widely accepted that DNA methylation marks are functionally complex and may orchestrate other important regulatory events, including alternative splicing and even the promotion of gene transcription [8]. However, we cannot rule out the 


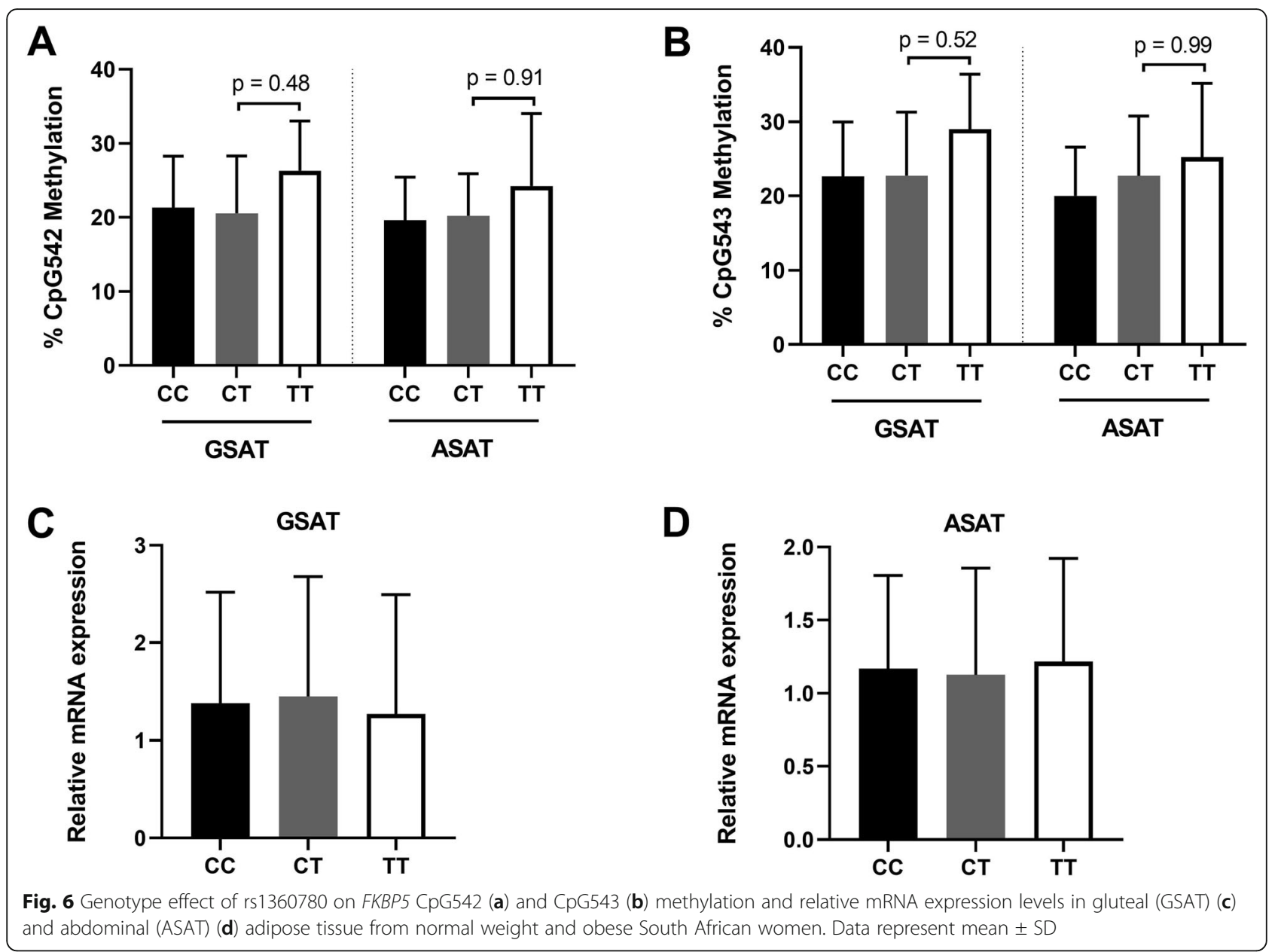

possibility of other genetic/epigenetic mechanisms underlying $G R$ regulation in this study, such as the presence of SNPs or inhibition by non-coding RNAs and/or histone modifications $[22,35]$.

While FKBP5 has been extensively studied in the context of neuropsychiatric diseases [5, 36-39], several recent studies have uncovered a metabolic role for this gene [40]. Indeed, preclinical studies using animal models have demonstrated that deletion of the FKBP5 gene protects mice from diet-induced obesity and hepatic steatosis, and pharmacological inhibition of FKBP5 improves their metabolic health $[41,42]$. In humans, genetic variants and hypomethylation within intron 2 of FKBP5 have been associated with Cushing's syndrome [24]. FKBP5 SNPs have also been linked to insulin resistance and T2D traits $[23,25]$ and reduced weight loss following bariatric surgery [43]. More recently, hypermethylation of two CpG sites in FKBP5 intron 2 in peripheral blood were associated with metabolic risk and cardiovascular disease traits, including BMI and WC, in individuals with T2D [44]. While this study was limited by a small sample size, it agrees with our findings on the association between higher intronic FKBP5 methylation and an increased risk for obesity and insulin resistance.

In agreement with the longstanding association of DNA methylation with gene silencing, we observed that CpG542 and CpG543 hypermethylation in obese women inversely correlated with FKBP5 transcript levels in GSAT. Although these CpGs do not reside within the proximal FKBP5 promoter, it is now appreciated that many steroid-regulated genes lack response elements in their promoters and are rather regulated through distal binding sites [45]. Furthermore, while it was beyond the scope of this study to elucidate the transcription factors that occupy and regulate this region, we note that CpG542 and CpG543 are located either directly within, or flank, biologically validated consensus glucocorticoid response elements (GREs), which have been shown to come into direct contact with the FKBP5 transcriptional start site and RNA polymerase II, via three-dimensional chromatin loops, and influence FKBP5 transcription [39]. In agreement with this are several reports demonstrating that exposure of human peripheral blood cells 
to dexamethasone, a GR agonist, can induce rapid demethylation and transcription of FKBP5 via these GREs $[5,46]$. Furthermore, while previous studies have shown that FKBP5 demethylation and mRNA induction by GR is influenced by the rs1360780 SNP in human peripheral blood from both African American and Caucasian populations [5, 46-48], this was not observed in our study, albeit in a limited sample size. These findings may suggest that FKBP5 regulation is tissue-specific; however, confirmation of this in larger, more representative studies is required.

Obesity is characterized by a state of chronic, lowgrade inflammation, which may be a key mechanism underlying the development of several obesity-associated diseases including T2D and CVD. Higher levels of inflammatory cytokines have been shown to cause a downregulation of GR expression and/or functionality of the receptor, resulting in glucocorticoid resistance, a condition characterized by insensitivity of tissues to the actions of glucocorticoids [49]. In adipose tissue, the development of glucocorticoid resistance by tumour necrosis factor $\alpha(\mathrm{TNF} \alpha)$ treatment was also shown to inhibit GR function by promoting the expression of GR $\beta$, a nuclear localized GR isoform which acts as a dominant negative of GR $\alpha$ transcriptional activity [50]. Interestingly, the obese women in our study had a more proinflammatory adipose tissue profile [51], including elevated expression levels of TNF $\alpha$ and migration inhibitory factor cytokines, as well as the CCL2 chemokine and macrophage markers, CD68 and CD163, which was accompanied by reduced GR $\alpha$ mRNA compared to normal weight women [51]. This observation corroborates

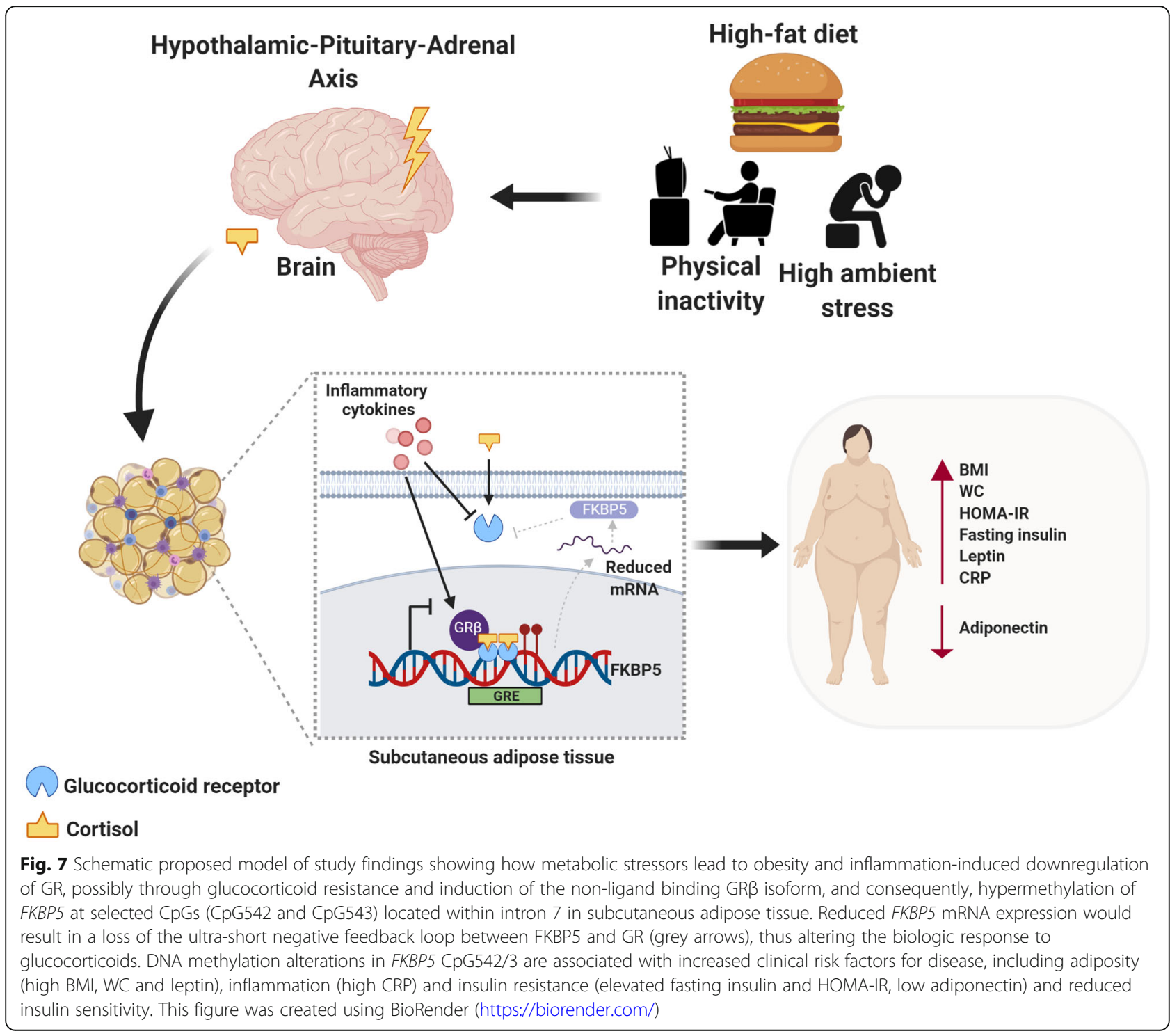


with other studies demonstrating a negative association between GR $\alpha$ mRNA levels and measures of inflammation, obesity and insulin resistance $[17,49,52]$.

Based on this, we propose a model whereby obesityand inflammation-induced downregulation of $G R$, and possible induction of GR $\beta$, may augment FKBP5 methylation and, consequently, reduce $F K B P 5$ transcription in GSAT (Fig. 7). These events, in turn, result in a loss of the ultra-short negative feedback loop between FKBP5 and GR, thus altering the biologic response to glucocorticoids. The change in glucocorticoid sensitivity in GSAT, triggered by low GR, may represent a beneficial feedback mechanism protecting adipocytes from dysregulated HPA axis activity during the progression of obesity and insulin resistance. It is unclear why $G R$ and FKBP5 mRNA levels were not similarly reduced in ASAT. It is possible that statistical significance was not obtained due to the use of a smaller sample size available for this tissue type. Alternatively, the effects on GR signaling may be dampened in this depot due to ethnic differences in inflammatory profiles of SAT between black and white women in our study population. Indeed, a previous study using the same sample population showed that GSAT from black women had higher expression of inflammatory cytokines, macrophage markers and leptin compared to ASAT [52].

Our study has several strengths. To our knowledge, this is the first study to assess both GR and FKBP5 DNA methylation in the same population of obese and normal weight individuals, providing a more comprehensive understanding of the interplay between these genes. Moreover, in contrast to most DNA methylation studies in obesity, we assessed GR and FKBP5 methylation levels in adipose tissue rather than peripheral blood. Adipose tissue is the primary affected organ during the development of obesity, and to date, few DNA methylation studies have been performed using this tissue type. The comparisons that were made between gluteal and abdominal SAT further strengthen this study, as they enabled the exploration of unique features that may contribute to the variability in associated metabolic risk between these depots. Indeed, notable differences in the magnitude of metabolic risk associations (as determined by multivariable regression $\beta$ coefficients) were observed for CpG542 in ASAT and GSAT, whereas the $\beta$-coefficients for CpG543 associations were relatively similar between depots. This observation raises the possibility that the role of CpG543 methylation is more highly conserved between the different adipose depots compared to CpG542, although additional experiments are required to confirm this.

Several limitations should also be noted when interpreting the results of this study. Firstly, adipose tissue contains a vascular-stromal fraction in which macrophages, fibroblasts, endothelial cells and preadipocytes reside, and we therefore cannot exclude the possible contribution of these cell types to the DNA methylation profiles obtained for GR and FKBP5 in our study. While we acknowledge that many studies using whole blood, for example, control for cellular heterogeneity by measuring DNA methylation in individual cell types following cell sorting or adjusting for direct measured cell counts, we were unable to do this in our study due to limited availability of tissue. Furthermore, whereas the use of post hoc regression models to adjust for blood cell mixture is facilitated by the availability of reference datasets on cell types in blood, to the best of our knowledge, such reference datasets are not available for adipose tissue and also may not be representative of our study population [53]. Another study limitation is the use of only female participants from South Africa, and therefore, the generalizability to other race/ethnic groups, or males, is unknown. Furthermore, as a result of our cross-sectional study design, the causal relationship between methylation changes and obesity or metabolic traits cannot be determined, and these warrant further investigation in larger, longitudinal study cohorts. While pyrosequencing is a highly sensitive and reliable method for DNA methylation analysis, it only allows for the investigation of small genomic regions [54]. It is therefore possible that our analysis does not reflect the methylation effect of other genomic regions of GR and FKBP5. In particular, FKBP5 contains numerous transcriptional regulatory regions which are distributed throughout the gene, including the promoter and other intronic enhancer regions which harbour functional GREs $[5,46]$ as well as CCCTC-binding factor (CTCF) sites [46]. Our analysis of the effect of the rs1360780 SNP on FKBP5 methylation and gene expression levels should also be interpreted in the context of a small sample size, and larger, more representative studies will be required to confirm this finding. Lastly, the molecular function of FKBP5 in adipose tissue during the progression of obesity remains to be elucidated. FKBP5 knockout adipocyte cell culture models may shed light on this and forms part of future studies.

\section{Conclusions}

Our study findings provide the first demonstration of an association between FKBP5 methylation in intron 7 in SAT and established markers of obesity and metabolic risk $[55,56]$. While these findings are purely correlative and cannot be used to determine causality, they add to a growing list of studies marking aberrant DNA methylation of HPA axis genes as clinically meaningful risk factors for metabolic diseases [57]. Future studies using longitudinal cohorts should shed light on whether FKBP5 hypermethylation is a cause or consequence of metabolic dysregulation. Moreover, it remains to be determined whether altered FKBP5 methylation patterns in 
SAT are reflected in blood, which could be used to assess potential risk of developing metabolic disease. Given the long time-course of T2D development and the reversible nature of epigenetic changes, our results demonstrate the significance of the HPA axis in metabolic dysfunction and mark constituents of this pathway as potential targets for preventative and therapeutic interventions for obesity and its complications.

\section{Methods}

\section{Study population}

The study was approved by the Human Research Ethics Committee of the Faculty of Health Sciences of the University of Cape Town. The study sample consisted of 27 obese (body mass index $(\mathrm{BMI}) \geq 30 \mathrm{~kg} / \mathrm{m}^{2}$ ) and 27 normal weight (BMI $<25 \mathrm{~kg} / \mathrm{m}^{2}$ ) premenopausal, urbandwelling South African women who were recruited as previously described [28]. All participants were of selfreported European or Black African (Xhosa) ancestry (both parents), aged 18-45 years without any known diseases, were not pregnant or lactating and were not taking medication for diabetes, hypertension, human immunodeficiency virus/acquired immunodeficiency syndrome (HIV/AIDS) or other metabolic-related disorders. Informed, written consent was obtained from each participant prior to testing.

\section{Participants characteristics}

\section{Assessment of demographic and lifestyle factors}

Baseline information was obtained from participants using standardized questionnaires as previously described [28]. Briefly, questionnaire information included participant demographics, age, race, current smoking status, level of alcohol consumption (estimated using a food frequency questionnaire) and information on asset index, education level, household crowding and employment status which were used to calculate a socioeconomic score (SES) as previously described [51].

\section{Body composition}

Assessment of body composition was described in detail previously [28]. Basic anthropometric measurements including height, weight and waist circumference were recorded and BMI was calculated as weight $(\mathrm{kg}) /$ height $^{2}$ $\left(\mathrm{m}^{2}\right)$. Total fat mass and gluteal subcutaneous adipose was measured by dual-energy X-ray absorptiometry (DXA; Discovery-W, Software version 12.6; Hologic Inc., Bedford, MA, USA) while visceral and abdominal tissue mass was measured by computerized tomography (CT; Toshiba X-press Helical Scanner, Tokyo, Japan) [28].

\section{Biochemical and metabolic analysis}

After an overnight fast, blood samples were drawn for the measurement of plasma glucose and serum insulin concentrations, which were used to estimate insulin resistance, based on the homeostasis model of insulin resistance (HOMA-IR) [58]. Participants underwent an insulin-modified frequently sampled intravenous glucose tolerance test (FSIGT) as previously described [59], from which the insulin sensitivity index $\left(S_{\mathrm{I}}\right)$ was measured using Bergman's minimal model of glucose kinetics [60].

\section{Fat biopsies}

Adipose tissue biopsies were obtained from superficial abdominal subcutaneous adipose tissue (ASAT) and gluteal subcutaneous adipose tissue (GSAT) depots using a mini liposuction method as previously described [51]. The tissues were placed in vials, snap frozen in liquid nitrogen and stored at $-80^{\circ} \mathrm{C}$ for subsequent gene expression and DNA methylation analysis.

\section{DNA extraction}

Genomic DNA was extracted from GSAT and ASAT using the QIAamp DNA kit (Qiagen. Valencia, CA, USA) according to the manufacturer's instructions. DNA quality and concentrations were assessed using the NanoDrop ND-1000 Spectrophotometer (NanoDrop Products, Wilmington, USA) and Qubit fluorometer (Life Technologies, CA, USA), respectively.

\section{Bisulfite conversion}

Treatment of DNA with sodium bisulfite converts all unmethylated cytosine bases into uracil, allowing for the identification of methylated, unconverted cytosines by pyrosequencing [61]. Bisulfite conversion of genomic DNA from adipose tissue biopsies were performed using the EpiTect DNA kit (Qiagen, Hilden, Germany), according to the manufacturer's instructions. The following PCR conditions were used for the conversion: $95^{\circ} \mathrm{C}$ for $5 \mathrm{~min}, 60^{\circ} \mathrm{C}$ for $10 \mathrm{~min}, 95^{\circ} \mathrm{C}$ for $5 \mathrm{~min}, 60^{\circ} \mathrm{C}$ for 10 min and $4{ }^{\circ} \mathrm{C}$ for less than $20 \mathrm{~h}$. Bisulphite-treated DNA were desulphonated, washed and eluted prior to use in PCR and pyrosequencing experiments.

\section{Pyrosequencing}

Percent DNA methylation of GR and FKBP5 was determined by pyrosequencing. The $G R$ gene has nine alternative first exons that are controlled independently by separate promoters [15]. Exon 1F, situated within a 3-kb CpG island, is the most widely studied, and differential methylation of $\mathrm{CpGs}$ within this region has been previously associated with subclinical atherosclerosis [27]. Thus, for the current study, pyrosequencing assays were designed to this region. For FKBP5, we assessed CpG sites within introns 2 and 7 which span experimentally validated GREs and have previously been implicated in metabolic disorders [15, 24, 44]. All pyrosequencing assays were designed by EpigenDX (Worcester, MA, USA). PCR of 25 ng bisulfite converted DNA was carried out 
using the PyroMark PCR Kit (Qiagen, Valencia, CA, USA) under the following PCR conditions: GR (EpigenDX assay ADS1342): $95{ }^{\circ} \mathrm{C}$ for $15 \mathrm{~min} ; 45 \times\left(95^{\circ} \mathrm{C}\right.$ for $30 \mathrm{~s} ; 56{ }^{\circ} \mathrm{C}$ for $30 \mathrm{~s} ; 72{ }^{\circ} \mathrm{C}$ for $30 \mathrm{~s}$ ); $72{ }^{\circ} \mathrm{C}$ for $5 \mathrm{~min}$; GR (EpigenDX assay ADS2386): $95{ }^{\circ} \mathrm{C}$ for $15 \mathrm{~min} ; 45 \times$ $\left(95{ }^{\circ} \mathrm{C}\right.$ for $30 \mathrm{~s} ; 54{ }^{\circ} \mathrm{C}$ for $30 \mathrm{~s} ; 72{ }^{\circ} \mathrm{C}$ for $\left.30 \mathrm{~s}\right) ; 72{ }^{\circ} \mathrm{C}$ for 5 min; FKBP5 (EpigenDX assay ADS3269): $95^{\circ} \mathrm{C}$ for 15 min; $45 \times\left(95{ }^{\circ} \mathrm{C}\right.$ for $30 \mathrm{~s} ; 60{ }^{\circ} \mathrm{C}$ for $30 \mathrm{~s} ; 68{ }^{\circ} \mathrm{C}$ for $\left.30 \mathrm{~s}\right)$; $68{ }^{\circ} \mathrm{C}$ for $5 \mathrm{~min}$; FKBP5 (EpigenDX assay ADS3828): 95 ${ }^{\circ} \mathrm{C}$ for $15 \mathrm{~min} ; 45 \times\left(95{ }^{\circ} \mathrm{C}\right.$ for $30 \mathrm{~s} ; 56{ }^{\circ} \mathrm{C}$ for $30 \mathrm{~s} ; 68^{\circ} \mathrm{C}$ for $30 \mathrm{~s}) ; 68{ }^{\circ} \mathrm{C}$ for $5 \mathrm{~min}$. PCR reactions were carried out in a Veriti 96-well Thermal Cycler (Thermo Fisher, Waltham, MA, USA). The quality of PCR amplicons was assessed by agarose gel electrophoresis and amplicons were stored at $4^{\circ} \mathrm{C}$ until pyrosequencing. Singlestranded amplicons were annealed to pyrosequencing primers (EpigenDX, Worcester, MA, USA) and subjected to primer extension and nucleotide incorporation using the PyroMark Q96 MD pyrosequencer and PyroMark Gold Q95 reagents (Qiagen, Valencia, CA, USA) according to the manufacturer's instructions. Sequencing analysis was performed using the PyroMark Q96 software (Version 1.0.10; Qiagen) program, which determined percent DNA methylation at all CpG dinucleotides downstream of the annealed primer at > $90 \%$ precision. All pyrosequencing assays were validated using different ratios of methylated:unmethylated bisulfite converted DNA (0, 10, 25, 50, 75, 90 and 100\%) (Qiagen, Valencia, CA, USA), from which standard curves were constructed to determine primer sensitivity (Fig. S1). Pyrosequencing assay validation also included quality controls containing either of the following: sequencing primer and annealing buffer only; biotinylated PCR primer and annealing buffer only; sequencing primer, biotinylated PCR primer and annealing buffer only; PCR product and annealing buffer only; PCR no template control, sequencing primer and annealing buffer only. Each pyrosequencing run contained no template negative controls, and bisulfite conversion controls were incorporated within each assay sequence to assess conversion efficiency. Assays were repeated if any of the inbuilt quality control measures were flagged. The nomenclature of $G R$ and FKBP5 CpGs are based on their sequencing identities from EpigenDX (Worcester, MA, USA).

\section{RNA extraction, reverse transcription and real-time PCR}

Total RNA was extracted from GSAT and ASAT biopsies using the RNeasy/miRNeasy mini Kit (Qiagen, CA, USA) according to the manufacturer's instructions. RNA quantity and purity were determined using the NanoDrop ND-1000 Spectrophotometer (NanoDrop Products, DE, USA). Complementary DNA (cDNA) was synthesized using the High-Capacity cDNA Reverse
Transcription Kit (Applied Biosystems, CA, USA), and mRNA levels of FKBP5, GR and reference genes 18S, PPIA and RPLP0 quantified using TaqMan Universal PCR Master Mix and TaqMan gene expression assays (Applied Biosystems, CA, USA), according to the manufacturer's instructions. Relative expression levels were calculated using the standard curve method. Normfinder, a mathematical model of gene expression [62], was used to confirm the stable expression of the reference genes and identified RPLP0 as the best normalization gene. Thus, expression levels were normalized to the RPLP0 endogenous control.

\section{FKBP5 SNP genotyping}

The FKBP5 rs1360780 (C/T) polymorphisms were genotyped using qRT-PCR with Taqman genotyping assays (Applied Biosystems, Massachusetts, USA) on the QuantStudio $^{\text {Tn }} 7$ Flex Real-Time PCR System (Applied Biosystems, Massachusetts, USA). Briefly, qRT-PCR was performed using 9.4 ng of DNA, $5 \mu \mathrm{l}$ of Taqman Master Mix and $0.25 \mu \mathrm{l}$ of $40 \times$ TaqMan SNP genotyping assay in a total volume of $10 \mu \mathrm{l}$, according to the manufacturer's instructions. The following PCR conditions were used: 10 $\mathrm{min}$ at $95 \mathrm{C}$ (initial denaturation/enzyme activation), $15 \mathrm{~s}$ at $95 \mathrm{C}$ (denaturation) and $60 \mathrm{~s}$ at $60 \mathrm{C}$ (annealing/extension) for 40 cycles. For quality control, eight samples were randomly selected and genotyped in duplicate. Positive and negative controls were included on all plates.

\section{Statistical analysis}

Data are presented as the mean and standard deviation (SD) if normally distributed or the median and interquartile range (25th and 75th percentile) if not normally distributed. The Shapiro-Wilk test was used to test for normality. Student's $t$ tests (normal distribution) and Mann-Whitney tests (non-normal distribution) were used to compare anthropometric, metabolic and gene expression differences between obese and normal weight women. In order to explore site-specific DNA methylation differences between obese and normal weight women, as well as to examine associations with metabolic parameters, multivariable analysis was used. This analysis helps to avoid multiple comparisons and has the ability to deal with correlated variables. Firstly, the complete dataset was inspected using principal component analysis (PCA) to detect groupings and outliers. We then performed orthogonal partial least-squares discriminate analysis (OPLS-DA) to examine differences in site-specific DNA methylation between obese and normal weight women. The CpG sites that were differentially methylated between obese and normal weight women were then used in OPLS analysis to explore associations with measures of insulin sensitivity, body composition, plasma adipokines, systemic inflammation, sociodemographic and lifestyle factors. The models 
were validated based on analysis of variance (ANOVA) of the cross-validated OPLS scores (CV-ANOVA) for significance testing [63]. Variables were considered significant when fulfilling the statistical significance criteria using post hoc linear regression on loadings calculated from the validated OPLS models using a 95\% confidence level [64]. Multivariable linear regression was then conducted to explore the associations between the DNA methylation sites and the metabolic outcomes, adjusting for significant confounding factors, shown in the OPLS models. The correlation between differentially methylated CpG sites and mRNA levels, and association of mRNA levels with metabolic parameters, were assessed using Spearman's correlation analysis. Since mRNA levels did not correlate with lifestyle and sociodemographic variables, no post hoc adjustments were made for these data. Genotype-stratified DNA methylation and gene expression data were compared between obese and normal weight women using the non-parametric Kruskal-Wallis test. Hardy-Weinberg equilibrium of the genotyped FKBP5 SNP (rs1360780) was tested using a chi-square goodness of fit test. Data were analysed using STATA version 14.0 (StataCorp, College station, TX, USA), GraphPad Prism (v8.2.1) and SIMCA v. 15.02. Significance was accepted as $p<0.05$.

\section{Supplementary information}

Supplementary information accompanies this paper at https://doi.org/10. 1186/s13148-020-00932-3.

Additional file 1: Figure S1. Sensitivity of pyrosequencing assays used to interrogate GR and FKBP5. Standard curves for GR CpG-226 to CpG-217 (A), GR CpG-209 to CpG-202 (B), FKBP5 CpG -585 to CpG-573 (C) and FKBP5 CpG542 and CpG543 (D). Table S1. Correlation between DNA methylation and cardiometabolic risk factors. Data expressed as the $\beta$ coefficient ( $p$-value) adjusted for ethnicity, socioeconomic status and *alcohol consumption. Abbreviations: ASAT, abdominal subcutaneous adipose tissue; BMI, body mass index; CRP, c-reactive protein; GSAT, gluteal subcutaneous adipose tissue; HOMA-IR, Homeostatic model assessmentinsulin resistance; $S_{\text {I, }}$ insulin sensitivity index; WC, waist circumference. Table S2. Correlation between FKBP5 mRNA levels and cardiometabolic risk factors. Data expressed as the Spearman's r-coefficient ( $p$-value). Abbreviations: ASAT, abdominal subcutaneous adipose tissue; BMI, body mass index; CRP, c-reactive protein; GSAT, gluteal subcutaneous adipose tissue; HOMA-IR, Homeostatic model assessment-insulin resistance; SES, socioeconomic status, $S_{\text {, }}$ insulin sensitivity index; WC, waist circumference.

\section{Abbreviations}

ASAT: Abdominal subcutaneous adipose tissue; AUC: Area under the curve; BMI: Body mass index; CRP: C-reactive protein; CVD: Cardiovascular disease; FKBP5: FK506 binding protein 5; GR: Glucocorticoid receptor; GSAT: Gluteal subcutaneous adipose tissue; HOMA-IR: Homeostatic model of insulin resistance; OPLS: Orthogonal partial least-squares; OPLS-DA: Orthogonal partial least-squares discriminate analysis; PCA: Principle component analysis; PCR: Polymerase chain reaction; QRT-PCR: Quantitative real-time PCR; SAT: Subcutaneous adipose tissue; SES: Socioeconomic score; S: Insulin sensitivity index; TSS: Transcriptional start site; T2D: Type 2 diabetes; VAT: Visceral adipose tissue; WC: Waist circumference

\section{Authors' contributions}

TW contributed to the study design, laboratory work, data analysis, manuscript writing and manuscript revising. SD assisted with laboratory work. JG was responsible for the phenotype data. CP assisted with data analysis. CP and JG corrected the manuscript. All authors read and approved the final manuscript.

\section{Funding}

This work was supported by the South African Medical Research Council (SAMRC), the National Research Foundation professional development program (PDP) (Grant number: 104987 awarded to TW) and the International Atomic Energy agency. The content hereof is the sole responsibility of the authors and does not necessarily represent the official views of the SAMRC or the funders.

\section{Availability of data and materials}

The datasets used and/or analysed during the current study are available from the corresponding author on reasonable request.

\section{Ethics approval and consent to participate}

This study was approved by the Research Ethics Committee of the Faculty of Health Sciences of the University of Cape Town and written informed consent to participate in the study was obtained from all subjects prior to participation in the study.

\section{Consent for publication}

Not applicable.

\section{Competing interests}

The authors declare that the research was conducted in the absence of any commercial or financial relationships that could be construed as a potential conflict of interest.

\section{Author details}

'Biomedical Research and Innovation Platform, South African Medical Research Council, Tygerberg 7505, South Africa. ${ }^{2}$ Division of Medical Physiology, Faculty of Health Sciences, Stellenbosch University, Tygerberg 7505, South Africa. ${ }^{3}$ Non-Communicable Diseases Research Unit, South African Medical Research Council, Tygerberg 7505 , South Africa. ${ }^{4}$ Division of Exercise Science and Sports Medicine, Department of Human Biology, University of Cape Town, Boundary Road, Newlands 7700, South Africa. ${ }^{5}$ Department of Biochemistry and Microbiology, University of Zululand, Kwa-Dlangezwa 3886, South Africa.

Received: 22 April 2020 Accepted: 1 September 2020 Published online: 21 September 2020

\section{References}

1. Gonzalez-Muniesa P, Martinez-Gonzalez MA, Hu FB, Despres JP, Matsuzawa Y, Loos RJF, et al. Obesity. Nat Rev Dis Primers. 2017;3:17034.

2. Rutters F, La Fleur S, Lemmens S, Born J, Martens M, Adam T. The hypothalamic-pituitary-adrenal axis, obesity, and chronic stress exposure: foods and HPA axis. Curr Obes Rep. 2012;1 (4):199-207.

3. Lee RA, Harris CA, Wang JC. Glucocorticoid receptor and adipocyte biology. Nucl Receptor Res. 2018;5.

4. Zannas AS, Wiechmann T, Gassen NC, Binder EB. Gene-stress-epigenetic regulation of FKBP5: clinical and translational implications. Neuropsychopharmacology. 2016;41(1):261-74.

5. Klengel T, Mehta D, Anacker C, Rex-Haffner M, Pruessner JC, Pariante CM, et al. Allele-specific FKBP5 DNA demethylation mediates gene-childhood trauma interactions. Nat Neurosci. 2013;16(1):33-41.

6. Fries GR, Vasconcelos-Moreno MP, Gubert C, BTMQd S, Sartori J, Eisele B, et al. Hypothalamic-pituitary-adrenal axis dysfunction and illness progression in bipolar disorder. Int J Neuropsychopharmacol. 2014;18(1):pyu043.

7. Farrell C, Doolin K, O'Leary N, Jairaj C, Roddy D, Tozzi L, et al. DNA methylation differences at the glucocorticoid receptor gene in depression are related to functional alterations in hypothalamic-pituitary-adrenal axis activity and to early life emotional abuse. Psychiatry Res. 2018;265:341-8.

8. Jones PA. Functions of DNA methylation: islands, start sites, gene bodies and beyond. Nat Rev Genet. 2012;13(7):484-92.

9. Jiang X, Wang Z, Ding B, Yin C, Zhong Q, Carter BZ, et al. The hypomethylating agent decitabine prior to chemotherapy improves the 
therapy efficacy in refractory/relapsed acute myeloid leukemia patients. Oncotarget. 2015;6(32):33612-22.

10. Vogel MAA, Jocken JWE, Sell H, Hoebers N, Essers Y, Rouschop KMA, et al. Differences in upper and lower body adipose tissue oxygen tension contribute to the adipose tissue phenotype in humans. J Clin Endocrinol Metab. 2018;103(10):3688-97.

11. Keller M, Hopp L, Liu X, Wohland T, Rohde K, Cancello R, et al. Genomewide DNA promoter methylation and transcriptome analysis in human adipose tissue unravels novel candidate genes for obesity. Mol Metab. 2017; 6(1):86-100.

12. Ma X, Lee P, Chisholm DJ, James DE. Control of adipocyte differentiation in different fat depots; implications for pathophysiology or therapy. Front Endocrinol. 2015;6:1.

13. Vogel MAA, Wang P, Bouwman FG, Hoebers N, Blaak EE, Renes J, et al. A comparison between the abdominal and femoral adipose tissue proteome of overweight and obese women. Sci Rep. 2019;9(1):4202.

14. Zwamborn RA, Slieker RC, Mulder PC, Zoetemelk I, Verschuren L, Suchiman $\mathrm{HE}$, et al. Prolonged high-fat diet induces gradual and fat depot-specific DNA methylation changes in adult mice. Sci Rep. 2017;7:43261.

15. Argentieri MA, Nagarajan S, Seddighzadeh B, Baccarelli AA, Shields AE. Epigenetic pathways in human disease: the impact of DNA methylation on stress-related pathogenesis and current challenges in biomarker development. EBioMedicine. 2017;18:327-50.

16. Balsevich G, Uribe A, Wagner KV, Hartmann J, Santarelli S, Labermaier C, et al. Interplay between diet-induced obesity and chronic stress in mice: potential role of FKBP51. J Endocrinol. 2014;222(1):15-26.

17. Castro RB, Longui CA, Faria CD, Silva TS, Richeti F, Rocha MN, et al. Tissuespecific adaptive levels of glucocorticoid receptor alpha mRNA and their relationship with insulin resistance. Genet Mol Res. 2012;1 1(4):3975-87.

18. Fichna M, Krzysko-Pieczka I, Zurawek M, Skowronska B, JanuszkiewiczLewandowska D, Fichna P. FKBP5 polymorphism is associated with insulin resistance in children and adolescents with obesity. Obes Res Clin Pract. 2018;12(Suppl 2):62-70.

19. Goedecke JH, Chorell E, Livingstone DE, Stimson RH, Hayes P, Adams K, et al. Glucocorticoid receptor gene expression in adipose tissue and associated metabolic risk in black and white south African women. Int Obes. 2015;39(2):303-11.

20. John K, Marino JS, Sanchez ER, Hinds TD Jr. The glucocorticoid receptor: cause of or cure for obesity? Am J Physiol Endocrinol Metab. 2016;310(4):E249-57.

21. Laryea G, Schütz G, Muglia L. Disrupting hypothalamic glucocorticoid receptors causes HPA axis hyperactivity and excess adiposity. Mol Endocrinol. 2013;27(10):1655-65.

22. Majer-Lobodzinska A, Adamiec-Mroczek J. Glucocorticoid receptor polymorphism in obesity and glucose homeostasis. Adv Clin Exp Med. 2017;26(1):143-8.

23. Pereira MJ, Palming J, Svensson MK, Rizell M, Dalenback J, Hammar M, et al. FKBP5 expression in human adipose tissue increases following dexamethasone exposure and is associated with insulin resistance. Metabolism. 2014;63(9):1198-208.

24. Resmini E, Santos A, Aulinas A, Webb SM, Vives-Gilabert Y, Cox O, et al. Reduced DNA methylation of FKBP5 in Cushing's syndrome. Endocrine. 2016;54(3):768-77.

25. Sidibeh CO, Pereira MJ, Abalo XM, Boersma GJ, Skrtic S, Lundkvist P, et al. FKBP5 expression in human adipose tissue: potential role in glucose and lipid metabolism, adipogenesis and type 2 diabetes. Endocrine. 2018;62(1):116-28.

26. Zannas AS, Jia M, Hafner K, Baumert J, Wiechmann T, Pape JC, et al. Epigenetic upregulation of FKBP5 by aging and stress contributes to NFkappaB-driven inflammation and cardiovascular risk. Proc Natl Acad Sci U S A. 2019;116(23):11370-9.

27. Zhao J, An Q, Goldberg J, Quyyumi AA, Vaccarino V. Promoter methylation of glucocorticoid receptor gene is associated with subclinical atherosclerosis: a monozygotic twin study. Atherosclerosis. 2015;242(1):71-6.

28. Goedecke JH, Levitt NS, Lambert EV, Utzschneider KM, Faulenbach MV, Dave $J A$, et al. Differential effects of abdominal adipose tissue distribution on insulin sensitivity in black and white south African women. Obesity. 2009; 17(8):1506-12

29. Zhao J, Goldberg J, Vaccarino V. Promoter methylation of serotonin transporter gene is associated with obesity measures: a monozygotic twin study. Int J Obes. 2013;37(1):140-5.

30. Frigola J, Song J, Stirzaker C, Hinshelwood RA, Peinado MA, Clark SJ. Epigenetic remodeling in colorectal cancer results in coordinate gene suppression across an entire chromosome band. Nat Genet. 2006;38(5):540-9.
31. Novak P, Jensen T, Oshiro MM, Watts GS, Kim CJ, Futscher BW. Agglomerative epigenetic aberrations are a common event in human breast cancer. Cancer Res. 2008;68(20):8616-25.

32. Leenen FA, Muller CP, Turner JD. DNA methylation: conducting the orchestra from exposure to phenotype? Clin Epigenetics. 2016;8:92.

33. Daskalakis NP, Yehuda R. Site-specific methylation changes in the glucocorticoid receptor exon $1 \mathrm{~F}$ promoter in relation to life adversity: systematic review of contributing factors. Front Neurosci. 2014;8:369.

34. Schur RR, Boks MP, Rutten BPF, Daskalakis NP, de Nijs L, van Zuiden M, et al. Longitudinal changes in glucocorticoid receptor exon $1 \mathrm{~F}$ methylation and psychopathology after military deployment. Transl Psychiatry. 2017;7(7):e1181.

35. Kadmiel M, Cidlowski JA. Glucocorticoid receptor signaling in health and disease. Trends Pharmacol Sci. 2013;34(9):518-30.

36. Breen ME, Gaynor SC, Monson ET, de Klerk K, Parsons MG, Braun TA, et al. Targeted sequencing of FKBP5 in suicide attempters with bipolar disorder. PLoS One. 2016;11(12):e0169158.

37. Matosin N, Halldorsdottir T, Binder EB. Understanding the molecular mechanisms underpinning gene by environment interactions in psychiatric disorders: the FKBP5 model. Biol Psychiatry. 2018;83(10):821-30.

38. Tyrka AR, Ridout KK, Parade SH, Paquette A, Marsit CJ, Seifer R. Childhood maltreatment and methylation of FK506 binding protein 5 gene (FKBP5). Dev Psychopathol. 2015;27(4 Pt 2):1637-45.

39. Yehuda R, Daskalakis NP, Bierer LM, Bader HN, Klengel T, Holsboer F, et al. Holocaust exposure induced intergenerational effects on FKBP5 methylation. Biol Psychiatry. 2016;80(5):372-80.

40. Baughman G, Wiederrecht GJ, Chang F, Martin MM, Bourgeois S. Tissue distribution and abundance of human FKBP51, an FK506-binding protein that can mediate calcineurin inhibition. Biochem Biophys Res Commun. 1997;232(2):437-43.

41. Stechschulte LA, Qiu B, Warrier M, Hinds TD, Zhang M. Gu H. FKBP51 null mice are resistant to diet-induced obesity and the PPARY agonist rosiglitazone. Endocrinology. 2016;157(10):3888-900.

42. Balsevich G, Hausl AS, Meyer CW, Karamihalev S, Feng X, Pohlmann ML, et al. Stress-responsive FKBP51 regulates AKT2-AS160 signaling and metabolic function. Nat Commun. 2017;8(1):1725.

43. Hartmann IBFG, Bucker J, Scotton E, von Diemen L, Kauer-Sant'Anna M. The FKBP5 polymorphism rs1360780 is associated with lower weight loss after bariatric surgery: 26 months of follow-up. Surg Obes Relat Dis. 2016;12(8):1554-60.

44. Ortiz R, Joseph JJ, Lee R, Wand GS, Golden SH. Type 2 diabetes and cardiometabolic risk may be associated with increase in DNA methylation of FKBP5. Clin Epigenetics. 2018:10:82.

45. McDowell IC, Barrera A, D'Ippolito AM, Vockley CM, Hong LK, Leichter SM, et al. Glucocorticoid receptor recruits to enhancers and drives activation by motif-directed binding. Genome Res. 2018;28(9):1272-84.

46. Wiechmann T, Röh S, Sauer S, Czamara D, Arloth J, Ködel M, et al. Identification of dynamic glucocorticoid-induced methylation changes at the FKBP5 locus. Clin Epigenetics. 2019;11(1):83.

47. Binder EB, Salyakina D, Lichtner P, Wochnik GM, Ising M, Putz B, et al. Polymorphisms in FKBP5 are associated with increased recurrence of depressive episodes and rapid response to antidepressant treatment. Nat Genet. 2004;36(12):1319-25.

48. Fujii T, Hori H, Ota M, Hattori K, Teraishi T, Sasayama D, et al. Effect of the common functional FKBP5 variant (rs1360780) on the hypothalamicpituitary-adrenal axis and peripheral blood gene expression. Psychoneuroendocrinology. 2014;42:89-97.

49. Cohen S, Janicki-Deverts D, Doyle WJ, Miller GE, Frank E, Rabin BS, et al. Chronic stress, glucocorticoid receptor resistance, inflammation, and disease risk. Proc Natl Acad Sci U S A. 2012;109(16):5995-9.

50. Webster JC, Oakley RH, Jewell CM, Cidlowski JA. Proinflammatory cytokines regulate human glucocorticoid receptor gene expression and lead to the accumulation of the dominant negative beta isoform: a mechanism for the generation of glucocorticoid resistance. Proc Natl Acad Sci U S A. 2001;98(12):6865-70.

51. Evans J, Goedecke JH, Soderstrom I, Buren J, Alvehus M, Blomquist C, et al. Depot- and ethnic-specific differences in the relationship between adipose tissue inflammation and insulin sensitivity. Clin Endocrinol. 2011;74(1):51-9.

52. Goedecke JH, Wake DJ, Levitt NS, Lambert EV, Collins MR, Morton NM, et al. Glucocorticoid metabolism within superficial subcutaneous rather than visceral adipose tissue is associated with features of the metabolic syndrome in south African women. Clin Endocrinol. 2006;65(1):81-7.

53. Fraser HB, Lam LL, Neumann SM, Kobor MS. Population-specificity of human DNA methylation. Genome Biol. 2012;13(2):R8. 
54. Sestakova S, Salek C, Remesova H. DNA methylation validation methods: a coherent review with practical comparison. Biol Proced Online. 2019;21:19.

55. Singh B, Saxena A. Surrogate markers of insulin resistance: a review. World J Diabetes. 2010;1(2):36-47.

56. Klein S, Allison DB, Heymsfield SB, Kelley DE, Leibel RL, Nonas C, et al. Waist circumference and cardiometabolic risk: a consensus statement from shaping America's health: Association for Weight Management and Obesity Prevention; NAASO, the Obesity Society; the American Society for Nutrition; and the American Diabetes Association. Am J Clin Nutr. 2007;85(5):1197-202.

57. Rosmond R, Bjorntorp P. The hypothalamic-pituitary-adrenal axis activity as a predictor of cardiovascular disease, type 2 diabetes and stroke. J Intern Med. 2000;247(2):188-97

58. Matthews DRHJ, Rudenski AS, Naylor BA, Treacher DF, Turner RC. Homeostasis model assessment: insulin resistance and beta-cell function from fasting plasma glucose and insulin concentrations in man. Diabetologia. 1985;28(7):412-9.

59. Goedecke JH, Dave JA, Faulenbach MV, Utzschneider KM, Lambert EV, West $\mathrm{S}$, et al. Insulin response in relation to insulin sensitivity: an appropriate beta-cell response in black south African women. Diabetes Care. 2009;32(5): $860-5$.

60. Bergman RN, Bortolan G, Cobelli C, Toffolo G. Identification of a minimal model of glucose disappearance for estimating insulin sensitivity. IFAC Proceedings Volumes. 1979;12(8):883-90.

61. Li Y, Tollefsbol TO. DNA methylation detection: bisulfite genomic sequencing analysis. Methods Mol Biol. 2011;791:11-21.

62. Vandesompele J, De Preter K, Pattyn F, Poppe B, Van Roy N, De Paepe A, et al. Accurate normalization of real-time quantitative RT-PCR data by geometric averaging of multiple internal control genes. Genome Biol. 2002; 3(7):Research0034.

63. Eriksson L, Trygg J, Wold S. CV-ANOVA for significance testing of PLS and OPLS models. J Chemom. 2008;22(11-12):594-600.

64. Jonsson P, Björkblom B, Chorell E, Olsson T, Antti H. Statistical loadings and latent significance simplify and improve interpretation of multivariate projection models. bioRxiv. 2018:350975.

\section{Publisher's Note}

Springer Nature remains neutral with regard to jurisdictional claims in published maps and institutional affiliations.

Ready to submit your research? Choose BMC and benefit from:

- fast, convenient online submission

- thorough peer review by experienced researchers in your field

- rapid publication on acceptance

- support for research data, including large and complex data types

- gold Open Access which fosters wider collaboration and increased citations

- maximum visibility for your research: over $100 \mathrm{M}$ website views per year

At $\mathrm{BMC}$, research is always in progress.

Learn more biomedcentral.com/submissions 